\title{
Preoperative Neutrophil Lymphocyte Ratio as a Prognostic Factor for Survival in Non-metastatic Renal Cell Carcinoma
}

\author{
J. CHINDAPRASIRT, W. SIRITHANAPHOL ${ }^{* *}$
}

Medical Oncology Unit, Department of Internal Medicine, Faculty of Medicine, Khon Kaen University, Khon Kaen, 1Division of Urology, Department of Surgery, Faculty of Medicine, Khon Kaen University, Thailand

Chindaprasirt and Sirithanaphol: Neutrophil Lymphocyte Ratio in Non-metastatic Renal Cell Carcinoma

The purpose of this study was to determine the prognostic role of preoperative neutrophil lymphocyte ratio in non-metastatic renal cell carcinoma. This retrospective study included 89 non-metastatic renal cell carcinoma patients who underwent nephrectomy between 2007 and 2017. The cut-off value of neutrophil lymphocyte ratio was determined on the basis of receiver operating characteristic analysis. Univariable and multivariable Cox regression models were performed. At a median follow-up of 6.7 y, 29 patients (34\%) had died. The cut-off value for neutrophil lymphocyte ratio was 2.5 by receiver operating characteristic analysis, with the area under the curve value of 0.77 . High neutrophil lymphocyte ratio was associated with high $T$ stage $(p=0.024)$. Elevated neutrophil lymphocyte ratio $(>2.5)$ was significantly associated with low overall survival. Multivariable analysis revealed that high preoperative neutrophil lymphocyte ratio was an independent risk factors for overall survival (hazard ratio 5.54, $95 \%$ confidence interval- 1.06-28.95, $p=0.043)$, along with age $>65(p=0.001)$ and large tumor size $(p<0.001)$. Preoperative neutrophil lymphocyte ratio is an independent prognostic factor for low overall survival in patients with non-metastatic renal cell carcinoma undergoing nephrectomy.

Key words: Kidney tumor, clear cell, renal surgery, prognosis, survival, neutrophil lymphocyte ratio

In the past decade, the treatment of renal cell carcinoma (RCC) has improved considerably with several new agents have been approved, including tyrosine kinase inhibitors and checkpoint inhibitors ${ }^{[1-4]}$. They have been shown to improve survival and quality of life in the metastatic setting, nevertheless, the 5 y overall survival rate is still disappointing. Detecting and treating the tumor in the early stage is the most promising way to a cure. In localized RCC, surgery is the main modality by either partial or radical nephrectomy. Studies addressing the role of adjuvant tyrosine kinase inhibitors after surgery have shown conflicting results ${ }^{[5-7]}$, thus potential markers for prognosis in resected RCC patients are warranted.

Carcinogenesis and tumor progression is linked to a tumor-associated inflammatory response ${ }^{[8]}$. Even in early-stage tumors, there is evidence of both local and systemic inflammation; including immune cell infiltration in the stroma, changes in peripheral blood cells, and alteration of inflammatory cytokines ${ }^{[9]}$. Neutrophil lymphocyte ratio (NLR) has been studied in many types of advanced cancer ${ }^{[10-12]}$ and has also gained the prognostic value in primarily operable tumors such as breast, colon and gastric cancer ${ }^{[13]}$. For localized RCC, there are only a few reports regarding the role of NLR as a prognostic factor. The aim of this research was to determine the prognostic role of NLR for survival in nonmetastatic RCC undergoing nephrectomy.

This retrospective cohort study was approved by the Khon Kaen University Faculty of Medicine Ethics Committee as instituted as per the Declaration of Helsinki (Number HE621159). All patients who underwent nephrectomy at Srinagarind Hospital, a large referral university hospital, between 1 January 2007 and 31 December 2017 were included. All patients were 18 y old or over and were diagnosed with RCC. Patients with distant organ metastasis were excluded. No patients received neoadjuvant and adjuvant 
treatment including targeted therapy, chemotherapy, or radiotherapy. Preoperative laboratory values were measured from peripheral blood samples. Anemia was defined according to WHO criteria ${ }^{[14]}$; hemoglobin $<13.0 \mathrm{~g} / \mathrm{dl}$ in males and $<12.0 \mathrm{~g} / \mathrm{dl}$ in females. NLR was calculated by dividing the absolute neutrophil count by the absolute lymphocyte count. Baseline and clinical characteristics were analyzed using descriptive statistics. Chi-square was used for categorical data. Receiver operating characteristic (ROC) analysis was constructed to assess the cut-off value of NLR. Date of diagnosis and date of death or last follow-up were collected from medical records. Overall survival (OS) was defined as a survival time from the date of renal cell carcinoma diagnosis to death from any cause. Survival analysis was performed using the Kaplan-Meier method and compared among groups using the logrank test. Univariable and multivariable Cox regression analyses of factors affecting survival were used. For all statistical comparisons, a p-value of less than 0.05 was considered statistically significant. All data analysis was performed using STATA software (StataCorp LP, College Station, TX, USA).

The baseline clinicopathological characteristics of the study patients are shown in Table 1 . The median age of the 89 patients was 58 y (range; 22-86). Onethird of patients $(36 \%)$ presented with hematuria and $25 \%$ of disease was found incidentally. Most of the tumors $(78.4 \%)$ were clear-cell subtype. Half of the patients were in T1 stage according to TNM staging 8 th edition ${ }^{[15]}$ and 3 patients were node positive. The NLR cut-off value for OS was 2.5, which yields the area under the curve (AUC) value of 0.77 (95\% CI- 0.66-0.89) with the sensitivity and specificity of 83.3 and $64.7 \%$, respectively.

The association of NLR and T stage is shown in Table 2 and fig. 1. The median level of NLR increased with higher $\mathrm{T}$ stage; $1.8,2.9,2.8$, and 3.6 from $\mathrm{T} 1$ to $\mathrm{T} 4$ respectively (fig. 2). NLR was significantly associated with $\mathrm{T}$ stage (Table 2). Sixty-three percent of patients with low T stage (T1 or T2) had low NLR $(<2.5)$, while $66.7 \%$ of high T stage (T3 or T4) had high NLR $(>2.5)$. The median follow-up duration was 6.7 y $(95 \% \mathrm{CI}$, 5.4-7.5 y). At the time of analysis, 29 patients (34.1\%) had died. The $3 \mathrm{y}, 5 \mathrm{y}$, and $10 \mathrm{y}$ survival rates were 74.5 (95\% CI; 63.5-82.6), 66.6 (95\% CI; 54.7-76.1) and $60.4 \%$ (95 \% CI; 47.5-71.1), respectively. The median OS was not reached (NR) (95\% CI; 7.4 y -NR). As shown in Table 3, factors significantly associated with shorter survival were old age ( $>65 \mathrm{y})$, low body mass index (BMI), large tumor size, anemia, and high NLR. The multivariable Cox proportional hazards model revealed that elevated preoperative NLR, age $>65 \mathrm{y}$ and large tumor size were independent factors for OS. The adjusted hazard ratio for high NLR was 5.54 (95\% CI, 1.06-28.95, p-value 0.043) as shown in fig. 2. Surgical resection is the mainstay of treatment for localized RCC, however, $20-30 \%$ of patients eventually developed recurrence or metastasis ${ }^{[16]}$. This study demonstrated that NLR was an independent prognostic factor of OS in non-metastatic RCC. This finding is consistent with earlier studies for early-stage RCC both clear cell and non-clear cell subtypes ${ }^{[17-21]}$. NLR has been shown to associate with worse OS as a continuous and categorical variable. The cut-off level varied among studies ranged from 1.7 to 4.0, which covered the threshold in this study ${ }^{[19-21]}$. Although BMI and anemia were significant in univariate analysis, only older age, tumor size, and NLR were significantly associated with OS on

\section{TABLE 1: CLINICOPATHOLOGICAL CHARACTERISTICS OF NON-METASTATIC RENAL CELL CARCINOMA PATIENTS ( $\mathrm{N}=89$ )}

\begin{tabular}{|c|c|}
\hline Characteristics & Number of patients (\%) \\
\hline Median age, years (range) & $58(22-86)$ \\
\hline \multicolumn{2}{|l|}{ Sex } \\
\hline Male & $59(66.3)$ \\
\hline Female & $30(33.7)$ \\
\hline \multicolumn{2}{|l|}{ Symptoms } \\
\hline Hematuria & $32(36.4)$ \\
\hline Flank pain & $19(21.6)$ \\
\hline Palpable mass & $15(17.0)$ \\
\hline Incidental finding & $22(25.0)$ \\
\hline Body mass index, $\mathrm{kg} / \mathrm{m}^{2}$ (range) & $23.4(16.2-39.3)$ \\
\hline \multicolumn{2}{|l|}{ Underlying disease } \\
\hline Hypertension & $30(33.7)$ \\
\hline Diabetes & $17(19.1)$ \\
\hline Chronic kidney disease & $30(33.7)$ \\
\hline Heart disease & $8(9.0)$ \\
\hline \multicolumn{2}{|l|}{ Histological subtype } \\
\hline Clear cell & $58(78.4)$ \\
\hline Papillary & $13(17.6)$ \\
\hline Chromophobe & $3(4.0)$ \\
\hline \multicolumn{2}{|l|}{ T stage } \\
\hline T1 & $38(49.3)$ \\
\hline T2 & $14(18.2)$ \\
\hline T3 & $23(29.9)$ \\
\hline T4 & $2(2.6)$ \\
\hline
\end{tabular}

TABLE 2: RELATIONSHIP BETWEEN NLR AND T STAGE

\begin{tabular}{lccc}
\hline & $\begin{array}{c}\text { Low stage } \\
(\text { T1/T2) }\end{array}$ & $\begin{array}{c}\text { High stage } \\
(\text { T3/T4) }\end{array}$ & p-value \\
\hline NLR & & & $0.024^{*}$ \\
Low $(<2.5)$ & $29(63.0 \%)$ & $7(33.3 \%)$ & \\
High $(\geq 2.5)$ & $17(37.0 \%)$ & $14(66.7 \%)$ & \\
\hline
\end{tabular}


multivariate analysis. Tumor grade and necrosis data, which are known tumor prognostic factors, could not be retrieved hence these were not included in the model. It was found that NLR was also associated with higher tumor stage and larger tumor size, which is similar to the earlier reports ${ }^{[21-23]}$. This could be explained by the increase in inflammation in the higher stage of the disease as higher neutrophil is also a poor prognostic marker in advanced RCC ${ }^{[24,25]}$. Recently there have been many studies to address the use of adjuvant therapy after nephrectomy in localized RCC to improve disease-free survival and OS. Adjuvant therapy, which included the first line agents such as tyrosine kinase inhibitors that significantly inhibit human protein

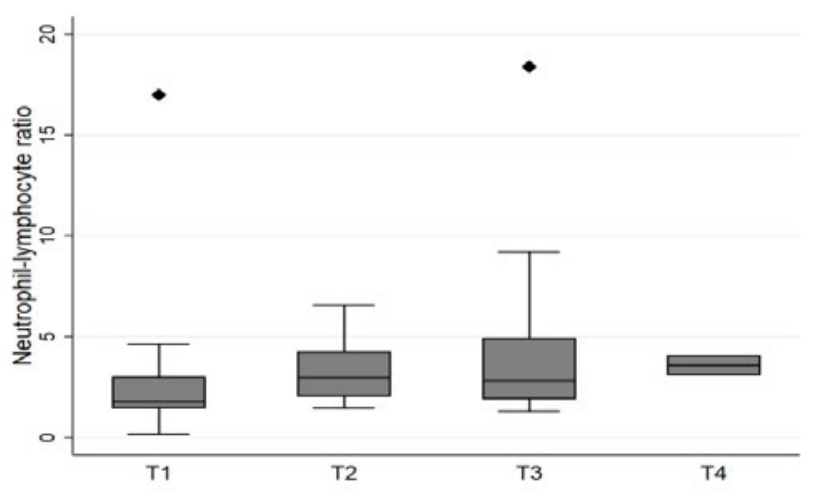

Fig. 1: Association between NLR and T stage

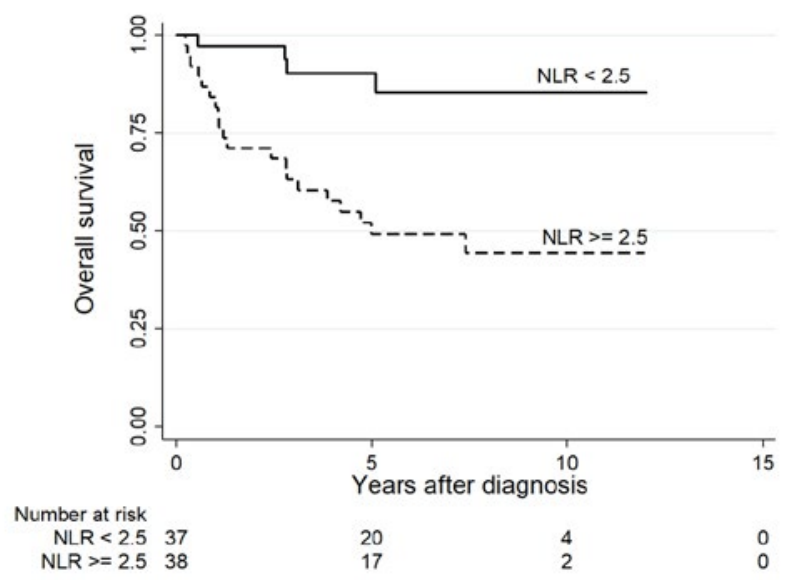

Fig. 2: Kaplan-Meier survival curve of patients with low and high NLR $(<2.5 \mathrm{vs}>2.5)$ tyrosine kinase, which has a central role in tumour carcinogenesis. Studies using tyrosine kinase inhibitors have shown conflicting results even in the high-risk group ${ }^{[5-7]}$. Adding immunotherapy, tumor vaccines and radiotherapy have all been explored with disappointing results ${ }^{[26,27]}$. It was believed that the selection of patients who would benefit the most from adjuvant treatment after surgery is essential and it was proposed that NLR might add value of predicting patients who might benefit from adjuvant treatment in addition to clinical parameters and molecular signatures ${ }^{[28]}$. The strength of this study was the long follow-up duration and the homogeneity of the specified treatment as no patient received neoadjuvant or adjuvant therapy and the surgical procedures were carried out by only 4 surgeons. The OS data were not confounded by the treatment after recurrence since only 6 patients received treatment with a tyrosine kinase inhibitor. For the reason that it is a retrospective study, pathological and biochemical data, which have been shown the prognostic role could not be completely collected. Despite this limitation, this study confirmed the prognostic role of preoperative NLR in non-metastatic RCC. There is scepticism that systemic inflammatory marker such as NLR might not be an useful predictor of recurrence progression in localized cancers. In summary, NLR is a poor prognostic factor for OS in patients with non-metastatic RCC undergoing nephrectomy. Preoperative measurement of NLR might be a convenient method to identify RCC patients with a poor prognosis. However, since this is an exploratory analysis, further confirmation of these results is required.

\section{Ethical approval:}

The study was approved by Khon Kaen University Faculty of Medicine Ethics Committee (Number HE621159).

\section{Data availability:}

The datasets generated during and/or analysed during

TABLE 3: UNIVARIABLE AND MULTIVARIABLE COX PROPORTIONAL HAZARDS MODEL FOR OVERALL SURVIVAL

\begin{tabular}{|c|c|c|c|c|c|c|}
\hline \multirow{2}{*}{ Factors } & \multicolumn{3}{|c|}{ Univariable } & \multicolumn{3}{|c|}{ Multivariable } \\
\hline & HR & $95 \% \mathrm{Cl}$ & p-value & HR & $95 \% \mathrm{Cl}$ & p-value \\
\hline Age $\geq 65$ & 2.25 & $1.08-4.69$ & $0.031^{*}$ & 22.04 & $3.77-128.71$ & $0.001^{*}$ \\
\hline $\mathrm{BMI}$ & 0.87 & $0.78-0.67$ & $0.012^{*}$ & 0.91 & 0.77-1.07 & 0.253 \\
\hline Tumor size & 1.19 & $1.10-1.29$ & $<0.001^{*}$ & 1.31 & $1.13-15.1$ & $<0.001^{*}$ \\
\hline Clear cell subtype & 0.73 & $0.35-1.52$ & 0.403 & 0.61 & $0.16-2.27$ & 0.458 \\
\hline Anemia & 4.14 & $1.41-12.12$ & $0.010^{*}$ & 1.63 & $0.29-9.21$ & 0.577 \\
\hline NLR $\geq 2.5$ & 5.43 & $1.86-15.90$ & $0.002^{*}$ & 5.54 & $1.06-28.95$ & $0.043^{*}$ \\
\hline
\end{tabular}

$\mathrm{BMI}$ is body mass index, NLR is neutrophil lymphocyte ratio, $\mathrm{HR}$ is hazard ratio and $\mathrm{Cl}$ is confidence interval 
the current study are available from the corresponding author on reasonable request.

\section{Conflict of interest:}

All authors declared that they have no conflict of interest in this work.

\section{REFERENCES}

1. Choueiri TK, Escudier B, Powles T, Mainwaring PN, Rini BI, Donskov $\mathrm{F}$, et al. Cabozantinib versus Everolimus in Advanced Renal-Cell Carcinoma. N Engl J Med 2015;373:1814-23.

2. Motzer RJ, Tannir NM, McDermott DF, Aren-Frontera O, Melichar B, Choueiri TK, et al. Nivolumab plus Ipilimumab versus Sunitinib in Advanced Renal-Cell Carcinoma. N Engl J Med. 2018;378:1277-90.

3. Motzer RJ, McCann L, Deen K. Pazopanib versus sunitinib in renal cancer. N Engl J Med 2013;369:722-31.

4. Motzer RJ, Penkov K, Haanen J, Rini B, Albiges L, Campbell MT, et al. Avelumab plus Axitinib versus Sunitinib for Advanced Renal-Cell Carcinoma. N Engl J Med 2019;380:1103-15.

5. Haas NB, Manola J, Uzzo RG, Flaherty KT, Wood CG, Kane $\mathrm{C}$, et al. Adjuvant sunitinib or sorafenib for high-risk, nonmetastatic renal-cell carcinoma (ECOG-ACRIN E2805): a double-blind, placebo-controlled, randomised, phase 3 trial. Lancet 2016;387:2008-16.

6. Motzer RJ, Haas NB, Donskov F, Gross-Goupil M, Varlamov S, Kopyltsov E, et al. Randomized Phase III Trial of Adjuvant Pazopanib Versus Placebo After Nephrectomy in Patients With Localized or Locally Advanced Renal Cell Carcinoma. J Clin Oncol 2017;35:3916-23.

7. Ravaud A, Motzer RJ, Pandha HS, George DJ, Pantuck AJ, Patel A, et al. Adjuvant Sunitinib in High-Risk Renal-Cell Carcinoma after Nephrectomy. N Engl J Med 2016;375:2246-54.

8. Hanahan D, Weinberg RA. Hallmarks of cancer: the next generation. Cell 2011;144:646-74.

9. Chechlinska M, Kowalewska M, Nowak R. Systemic inflammation as a confounding factor in cancer biomarker discovery and validation. Nat Rev Cancer 2010;10:2-3.

10. Vernieri C, Mennitto A, Prisciandaro M, Huber V, Milano M, Rinaldi L, et al. The neutrophil-to-lymphocyte and plateletto-lymphocyte ratios predict efficacy of platinum-based chemotherapy in patients with metastatic triple negative breast cancer. Sci Rep 2018;8:8703.

11. Yu Y, Wang H, Yan A, Wang H, Li X, Liu J, et al. Pretreatment neutrophil to lymphocyte ratio in determining the prognosis of head and neck cancer: a meta-analysis. BMC Cancer 2018;18:383.

12. Zhou Y, Wei Q, Fan J, Cheng S, Ding W, Hua Z. Prognostic role of the neutrophil-to-lymphocyte ratio in pancreatic cancer: A meta-analysis containing 8252 patients. Clinica Chimica acta 2018;479:181-9.

13. Roxburgh CS, McMillan DC. Role of systemic inflammatory response in predicting survival in patients with primary operable cancer. Future oncology 2010;6:149-63.

14. World Health Organization. Nutritional anaemias: Report of a WHO scientific group. Geneva, Switzerland: World Health Organization; 1968.

15. Amin M, Edge S, Greene F, Schilsky RL, Washington MK, Sullivan DC, et al. AJCC Cancer Staging Manual, Springer; 2017.
16. Lane BR, Kattan MW. Prognostic models and algorithms in renal cell carcinoma. Urol Clin N Am 2008;35:613-25.

17. Bazzi WM, Tin AL, Sjoberg DD, Bernstein M, Russo P. The prognostic utility of preoperative neutrophil-to-lymphocyte ratio in localized clear cell renal cell carcinoma. Can J Urol 2016;23:8151-4.

18. Dalpiaz O, Luef T, Seles M, Stotz M, Stojakovic T, Pummer $\mathrm{K}$, et al. Critical evaluation of the potential prognostic value of the pretreatment-derived neutrophil-lymphocyte ratio under consideration of $\mathrm{C}$-reactive protein levels in clear cell renal cell carcinoma. Br J Cancer 2017;116:85-90.

19. Grimes N, Hannan C, Tyson M, Thwaini A. The role of neutrophil-lymphocyte ratio as a prognostic indicator in patients undergoing nephrectomy for renal cell carcinoma. Can Urol Assoc J 2018;12:E345-e8.

20. Pichler M, Hutterer GC, Stoeckigt C, Chromecki TF, Stojakovic T, Golbeck S, et al. Validation of the pre-treatment neutrophil-lymphocyte ratio as a prognostic factor in a large European cohort of renal cell carcinoma patients. Br J Cancer 2013;108:901-7.

21. Wen RM, Zhang YJ, Ma S, Xu YL, Chen YS, Li HL, et al. Preoperative Neutrophil to Lymphocyte Ratio as a Prognostic Factor in Patients with Non-metastatic Renal Cell Carcinoma. Asian Pac J Cancer Prev 2015;16:3703-8.

22. Ceylan C, Camtosun A, Doluoglu OG, Tasdemir S, Keles I, Aglamis E, et al. Emphasis of neutrophil-to-lymphocyte ratio in non-metastatic renal cell carcinoma. Urologia 2014;81:51-6.

23. Hu H, Yao X, Xie X, Wu X, Zheng C, Xia W, et al. Prognostic value of preoperative NLR, dNLR, PLR and CRP in surgical renal cell carcinoma patients. World J Urol 2017;35:261-70.

24. Fox P, Hudson M, Brown C, Lord S, Gebski V, De Souza P, et al. Markers of systemic inflammation predict survival in patients with advanced renal cell cancer. Br J Cancer 2013;109:147-53.

25. Lucca I, de Martino M, Hofbauer SL, Zamani N, Shariat SF, Klatte T. Comparison of the prognostic value of pretreatment measurements of systemic inflammatory response in patients undergoing curative resection of clear cell renal cell carcinoma. World J Urol 2015;33:2045-52.

26. Chamie K, Donin NM, Klopfer P, Bevan P, Fall B, Wilhelm O, et al. Adjuvant Weekly Girentuximab Following Nephrectomy for High-Risk Renal Cell Carcinoma: The ARISER Randomized Clinical Trial. JAMA Oncol 2017;3:913-20.

27. Rodríguez-Fernández IA, Rodríguez-Romo L, HernandezBarajas D, Gonzalez-Conchas GA, Verdines-Perez A, Templeton AJ, et al. Adjuvant Radiation Therapy After Radical Nephrectomy in Patients with Localized Renal Cell Carcinoma: A Systematic Review and Meta-analysis. Eur Urol Oncol 2019;2:448-55.

28. Klatte T, Seligson DB, LaRochelle J, Shuch B, Said JW, Riggs $\mathrm{SB}$, et al. Molecular signatures of localized clear cell renal cell carcinoma to predict disease-free survival after nephrectomy. Cancer Epidemiol Biomarkers Prev 2009;18:894-900.

This is an open access article distributed under the terms of the Creative Commons Attribution-NonCommercial-ShareAlike 3.0 License, which allows others to remix, tweak, and build upon the work non-commercially, as long as the author is credited and the new creations are licensed under the identical terms

This article was originally published in a special issue, "Biomedical research applications in Pharmaceutical Sciences" Indian J Pharm Sci 2020:82(2)Spl issue3;66-69 